to Taxol by patients with tumors positive for p53 gene alterations may be variable, depending on the histotype or other genetic abnormalities.

DOMENico Delia ${ }^{1}$, SHUKi MizUTANi', GiUSEPPE LAMORTE ${ }^{3}$, KUMIKO GOI ${ }^{2}$, Satoshi IWATA $^{2} \&$ Marco A. Pierotti ${ }^{1}$
'Division OSA, Istituto Nazionale Tumori Via $G$ Venezian 1, 20133 Milano, Italy

'Department of Virology,

National Children's Medical Research Center

3-35-31 Taishido

Setagaya-ku, Tokyo 154, Japan

${ }^{3}$ Fondazione Matarelli, Via Durini 20,

20122 Milano, Italy
1. Wahl, A.F. et al. Loss of normal p53 function confers sensitization to Taxol by increasing G2/M arrest and apoptosis. Nature Med. 2, 72-79 (1996).

2. Hawkins, D.S., Demers, G.W. \& Galloway, D.A Inactivation of p53 enhances sensitivity to multiple chemotherapeutic agents. Cancer Res. 56, 892-898 (1996).

3. Wu, S.G. \& El-Deiry, W.S. p53 and chemosensitivity. Nature Med. 2, 255-256 (1996).

\title{
Plasminogen and wound healing
}

To the editor - Thompson et al. ${ }^{1}$ suggest that the impaired wound healing we recently reported in plasminogendeficient mice ${ }^{2}$ could be a result of diminished production of angiogenic fibrin degradation products (FDPs) and a subsequent impairment of cell proliferation including angiogenesis. Although this is certainly a viable hypothesis, it is important to recognize that we did not report and do not know that cell proliferation and angiogenesis are reduced in plasminogen knockout mice. Indeed, at least qualitatively, we observed both abundant formation of granulation tissue and pronounced neovascularization in these animals. In contrast, keratinocyte migration was markedly impaired and we proposed that this may be primarily because of a diminished ability of these cells to proteolytically dissect their way through the provisional fibrin-rich matrix.

A critical linkage between plasmingenerated FDPs and the establishment of vasculature seems generally inconsistent with the fact that both fibrinogen- and plasminogen-deficient mice develop to term and can grow to adulthood ${ }^{3,4}$. Nevertheless, Thompson et al.'s hypothesis of a critical role of biologically active FDPs in the context of wound repair, warrants further consideration. One way to discriminate between this concept and our proposal that the chief impediment to wound healing in plasminogendeficient mice is a fibrin barrier to cell migration is by studying wound healing in mice with a combined deficiency for both plasmin(ogen) and fibrin(ogen). Thompson et al.'s hypothesis predicts wound healing will remain impaired in these mice, whereas our hypothesis predicts that the impairment to wound healing observed in plasminogen-deficient mice will be alleviated or corrected if they also lack fibrinogen. Because mice with combined fibrinogen and plasminogen deficiency have been raised and shown to tolerate skin incisions, we expect this issue will be resolved shortly.

JOHN RøMER ${ }^{1}$, THOMAS H. BUGGE ${ }^{1,2}$, Charles Pyke ${ }^{1}$, Leif R. LUND ${ }^{1}$, Matthew J. Flick ${ }^{2}$, Jay L. Degen ${ }^{2}$ $\&$ KELD DAN $\varnothing^{1}$

'The Finsen Laboratory

Rigshospitalet, Strandboulevarden 49

DK-2100 Copenhagen $\varnothing$, Denmark

${ }^{2}$ Division of Developmental Biology

Children's Hospital Research Foundation

Cincinnati, Ohio 45229, USA

Thompson et al. reply - The experiments suggested by Rømer et al. will certainly be of interest regarding the mechanisms underlying wound healing, but what do we know that might predict the outcome? Plasminogen deficiency in wound healing has been studied in terms of incorporation of inhibitors of fibrinolysis within implanted fibrin clotss. Compared with controls, reduced invasion of granulation tissue but increased collagen deposition at the periphery were seen. Such a separation of emerging components of the granulation tissue may be relevant to the range of knockout mouse models now available and it will be important to examine the detailed temporal sequence of histopathological events.

Fibrinogen deficiency has been induced by Arvin defibrinogenation during experimental wound healing ${ }^{6}$. This reduces granulation tissue, which is also a feature of fetal wound healing. Fetal mouse wound closure occurs with minimal clot and macrophages because of the immature fetal coagulation system, by a mechanism of epidermal movement ${ }^{7}$. Another relevant factor is the long recognized chemotactic activity of fibrin degradation products $^{8}$. Therefore, we predict that the fibrinogen knockout mouse will exhibit epidermal closure with minimal true granulation tissue and minimal early inflammatory cell infiltrate. The combined plasminogen fibrinogen knockout should appear similar. However, "adding back" fibrin clot to the wound should restore all normal features to the fibrinogen-deficient mouse but only some of the granulation tissue component to the combined deficiencies mouse. "Adding back" fibrin fragment $E$, although difficult to envisage technically, should restore normal features to both types of mouse model.

W. DOUGLAS THOMPSON,

Chris M. STIRK, WilliaM T. MELVIN

\& ELSPETH B. SMITH

Departments of Pathology and

Molecular \& Cell Biology

University of Aberdeen, Medical School

Aberdeen Royal Infirmary, Aberdeen AB9, 2ZD, UK

1. Thompson, W.D., Stirk, C.M., Melvin, W.T. \& Smith, E.B. Plasmin, fibrin degradation and angiogenesis. Nature Med. 2, 493 (1996).

2. Rømer, J. et al. Impaired wound healing in mice with a disrupted plasminogen gene. Nature Med. 2, 287-292 (1996).

3. Bugge, T.H., Flick, M.J., Daugherty, C.C. \& Degen, J.L. Plasminogen deficiency causes severe thrombosis but is compatible with development and reproduction. Genes Dev. 9, 794-807 (1995)

4. Suh, T. et al. Resolution of spontaneous bleeding events but failure of pregnancy in fibrinogendeficient mice. Genes Dev. 9, 2020-2033 (1995).

5. Kwaan, H.C. \& Astrup, T. Tissue repair in presence of locally applied inhibitors of fibrinolysis. Exp. Molec. Pathol. 11, 82-88 (1969).

6. Bränsted, S. et al. Wound healing and formation of granulation tissue in normal and defibrinogenated rabbits. Eur. Surg. Res. 12, 12 (1980).

7. Martin, P. et al. Actin cables and epidermal movement in embryonic wound healing. Nature 360, 179-183 (1992).

8. Stecher, V.J. \& Sorkin, E. The chemotactic activity of fibrin lysis products. Int. Arch. Allergy 43, 879-886 (1972).

\section{LETTERS TO THE EDITOR}

Nature Medicine encourages brief letters to the editor (no more than $\mathbf{5 0 0}$ words) on topics that have been reported in previous issues or on subjects of interest to the biomedical research community. Letters should be addressed to Nature Medicine, 545 National Press Building, 529 14th Street NW, Washington, DC 20045, USA, or sent by fax (202.626.0970) or e-mail (medicine@naturedc.com). 